\title{
Development of Hard- and Software of Microseismic for Geothermal Exploration and Monitoring: First Results
}

\author{
Rachmat SULE ${ }^{1,3}$, David P. SAHARA ${ }^{1}$, Yosep KUSNADI ${ }^{2}$, Adrianto W. KUSUMO ${ }^{1}$, \\ Andri D. NUGRAHA ${ }^{1}$, Tedy SETIAWAN ${ }^{1}$, Sri WIDIYANTORO ${ }^{1}$, Toshifumi MATSUOKA ${ }^{3}$ \\ ${ }^{1}$ Study Program of Geophysical Engineering, Faculty of Mining and Petroleum Engineering, Institut Teknologi Bandung \\ ${ }^{2}$ Study Program of Geothermal Engineering, Faculty of Mining and Petroleum Engineering, Institut Teknologi Bandung \\ ${ }^{3}$ Environment and Resource System Engineering Lab., Dept. of Urban Management, Kyoto University
}

The Ministry of Research and Technology (RISTEK) of Republic Indonesia launched a so called "Riset Insentif RISTEK" since 2005. This allows Indonesian researchers to be active in research activities, which its funding is higher than other research funding available in Indonesia for small group of researchers. We received this kind of funding for the year of 2010 with its theme is development of hard- and software of microseismic for geothermal exploration and monitoring. This paper describes the first achievements after the funding is granted to us 8 (eight) months ago. This research theme is grouped into 3 main activities, namely development of borehole seismometer by using MEMS, development of precise microseismic relocation technique, and development of first arrival travel time tomography software. The overall current achievements are beyond the target of first year, so that the funding will be extended for the $2^{\text {nd }}$ year.

\section{INTRODUCTION}

This paper describes the current status of on-going research project, which is funded by "Riset Insentif RISTEK 2010" (or incentive research, granted by the Ministry of Research and Technology of Republic Indonesia). This research project is mainly about the efforts of developing hard- and software in order to explore and monitor the geothermal reservoir by using microseismic method. Indonesia has huge potential in providing the geothermal energy, nevertheless the usage of it, is not yet optimal. One of the causes is that the applied technology is still considered as a "high cost". Several efforts are done in order to suppress the cost of geothermal energy, namely if the exploration and monitoring technologies of geothermal reservoir could be done by domestic sector.

One of the methods in geothermal exploration and reservoir monitoring that has been developed and known worldwide is microseismic method. This method uses seismic wave sources in the earth subsurface, either natural or generated by stimulated injected fluids into reservoir. To implement this method, special microseismic receivers are needed. Development of this instrument is the first sub-topic that includes in this research framework. This instrument, which is still developed, will not only record the seismic wave arrival, but it includes also an effort to send those seismic data to observation post by wireless system as well.
The second sub-topic serves the development of software, which could determine the earthquake source locations in very high precision. This sub-topic adapts various researches that are already been developed before, namely "Hypocenter Relocation by using Double Differential method", or it is common known as Hypo-DD method.

Meanwhile, the third topic is describing the development of software, which will determine the earth subsurface condition based on $\mathrm{P}$ and $\mathrm{S}$ wave velocities within earth medium. The method that will be developed is the first arrival travel time tomography method.

If all of sub-topics that are still developed in this research could be done in two (2) years and resulted optimally; hence those technologies will be tested in various geothermal fields in Indonesia. The achievement that will be obtained will hopefully influence the effort of using alternate energy of geothermal, which is clean and renewable.

\section{DEVELOPMENT OF BOHRHOLE GEOPHONE}

We consider to develop instrumentation that could record microseismic events precisely. This instrumentation must be deployed on a certain depth in the field, in order to obtain better arrival of seismic signal. If the quality of seismic signal is high, off course microseismic processing and interpretation can be conducted in a better way. 
This type of receiver is called as 3C borehole geophone, and the development of this geophone is the first topic included in the research project.

Microseismic events for geothermal reservoir monitoring must receive frequencies of below $5 \mathrm{~Hz}$. This characteristic is the main consideration, which is normally not met in ordinary seismic events for oil and gas exploration. Ordinary geophone is difficult to detect such frequencies, except if several improvements are conducted to increase geophone bandwidth and to lower the frequecy treshold (Barzilai et. al., 1998).The price for developing coibased-geophones with those extra treatment is hundreds times expensive than the price of a normal geophone.

When the seismic wave arrives to a geophone, the coil will vibrate and caused DC potential difference, which is then described as seismic trace or seismic waveform. Unfortunately, every coil has its own harmonic frequency, which makes the coil vibrate in certain frequency after reacted by force (here, the force is equivalent to seismic wave). The harmonic vibration of the coil automatically affect the recorded signal, which make the signal consists not only the earth information but also the coil harmonic vibration. Thus, the use of coil-based geophone is not economically and suitable for geothermal monitoring purposes.

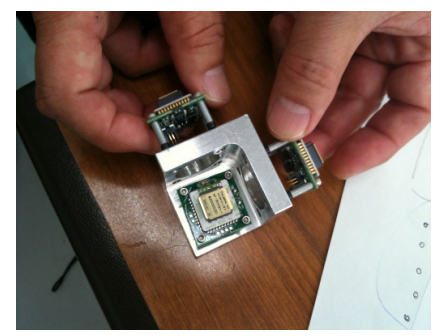

Figure 1: Three pieces of COLIBRYS MEMS S-1500-SN that are used for the development of 3C MEMS borehole seismometer. Here, the MEMS-seat can also be seen.

In this research project, we intend to replace the coil with MEMS (Micro Electro Mechanical System). MEMS is a device that consists of both mechanical and electronical systems, in which their sizes are in the range of micrometers. The device itself (MEMS) has a size of around $2 \times 2 \times 2 \mathrm{~cm}^{3}$. MEMS has already been applied in many devices around us and acts as a breakthrough in geophysical instrumentation. MEMS-based-geophone has shown significant improvements in obtaining geophysical data (Aizawa et. al., 2008). MEMS consists of microsensors and microactuators which are appropriately categorized as transducers. In microseismic acquisition, transducer converts pressure energy from seismic wave into an electrical signal through the change of the distance between capacitors' plates. The distance change between its gap will influence capacitors' capacity, which will then influence its impedance value and its DC voltage. This microsensor system doesn't have harmonical frequency since it does not vibrate. MEMS is built from silicon and glass which are more sensitive than metal (the main material of coil). Those substances makes MEMS-geophone has lower frequency treshold and wider frequency bandwidth than coil-based-geophone.

We use three units of single axis COLIBRYS MEMS of series S-1500-SN (see Fig. 1). The development of MEMS seismometer could be realized due to intensive discussions with Kyoto University and Suncoh Consultant Co. Ltd. in Japan. Those MEMSes are integrated by PCBs to control the desired output signal and will be attached into a solid case. The case itself will be equipped with clamping system, in order to obtain steady position inside the borehole. The diameter of this entire borehole geophone will be not more than 3 inch, thus it can fit for exploration borehole.

In the future, the ouput signal of the developed geophone will be compared and calibrated to a three axis COLIBRYS MEMS accelerometer of SF-3000-L and commercial borehole seismometer, e.g. DSS-6 Acquisition Unit. During assembly of this equipment, we have also to cope with environmental conditions, such as the probability of rising hot acid fluids, increasing temperature gradient, noise from upper ground and up to 5 Richter earthquakes which probably will collapse the geophone in the borehole.

\section{DEVELOPMENT OF HYPO-DD SOFTWARE}

The recent achievement of this sub research topic is beyond the target of $1^{\text {st }}$ year. This could be realized due to previous extensive cooperation with researchers from Tohoku University. Two research members learnt this method directly from Dr. H. Asanuma, one of pioneers of this method. Only after several months of development process, an efficient relative relocation program that is able to give significant improvement in hypocenter location can be produced.

Concept of the Hypo-DD method is based on the fact that if the hypocenter separation between two earthquakes is small compared to the events-station separation, the waveforms and ray paths of both events will be similar. Thus the difference of two events can be attributed to the spatial offset between the events with high accuracy. This could be valid, 
because the absolute errors have a common origin, except in the small region where the ray paths differ at the sources (Waldhauser and Ellsworth, 2000).

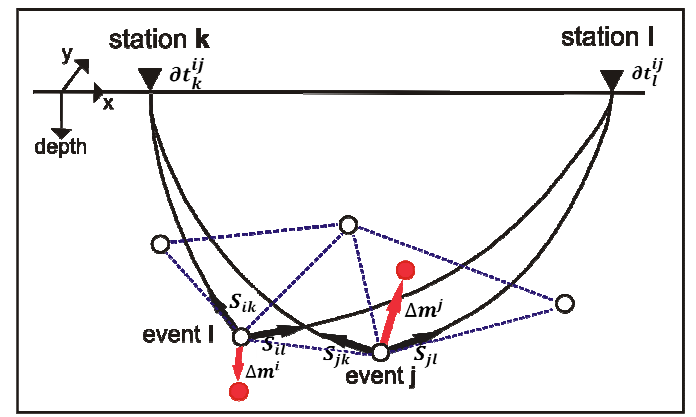

Figure 2: Illustration of the double-difference earthquake relocation algorithm. Hypocenter $i$ and $j$ relocated together in DD algorithm as a pair events to the station $\mathrm{k}$ and station (Waldhauser and Ellsworth, 2000).

The residual between observed and calculated differential travel time between the two events defined as,

$$
d r_{k}^{i j}=\left(t_{k}^{i}-t_{k}^{j}\right)^{o b s}-\left(t_{k}^{i}-t_{k}^{j}\right)^{c a l}
$$

where, $t^{\mathrm{obs}}$ and $t^{\mathrm{cal}}$ are the observed and theoretical travel times, from the difference between travel time event $\mathrm{i}$ and $\mathrm{j}$ to station $\mathrm{k}$.

Microseismic multiplet analysis has been applied to improve relative source location accuracy. This method can illuminate the detailed fracture system and physical phenomena associated with microseismicity by characterizing the waveform similarity of microseismic events. Then the events are relocated using the DD source location technique, and the reservoir structure is imaged using the spatial distribution of coherent microseismic events (Asanuma et. al., 2006).

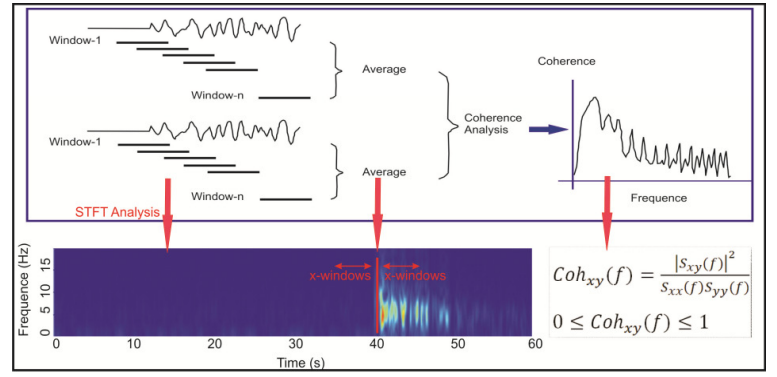

Figure 3: Illustration of the waveform similarity characterization (Asanuma et al., 2006).

The test of this program has been carried out by conducting synthetic case study (Sahara et. al, 2010). In this case study, it is assumed that the reservoir is injected by fluid. During this process, the microseismic instrumentation is installed on the surface in order to record the events. After the inversion is carried out, this method is able to give significant improvement in hypocenter location trends, which could be correlated with the flowing of fluid during injection.

After the program is tested by synthetic data and then validated by using determined relocation events from Soultz geothermal field in French, the first application to real data is carried out by using microseismic data from the Kelud volcano during its activity in September - November 2007 (Sahara et. al.,2010). From this study, it has been shown that the algorithm could collapse the diffused event location obtained from Single Event Determination (SED) into a sharp image of seismicity structure. As a result, narrow regions on the fault and fracture can be determined more accurately.

The most recent application of Hypo-DD has been conducted to relocate the earthquake events that are recorded during MERAMEX (MERapi AMphibious EXperiments) data acquisition in Central Java for around 150 days during May October 2004 (Koulakov et. al., 2007). A network consisting of 169 seismographic stations was installed onshore and offshore in Central Java and 282 events are recorded during the operation. The main purpose of this study is to map detailed and reliable image of subduction process beneath the volcanic chain in central Java.

The preliminary results showed that the algorithm has an ability to produce sharper image of seismicity structure and reduce the residual travel time error significantly $(7-60 \%)$. As a result (see Fig. 4), narrow regions of the double seismic zone which correlated with the subducting slab can be determined more accurately. The dipping angle of the slab increases gradually from almost horizontal beneath offshore to very steeply $\left(65^{\circ}-80^{\circ}\right)$ beneath the northern of Java. The aseismic gap at depths of $140 \mathrm{~km}-185 \mathrm{~km}$ are also shown fairly clearly.

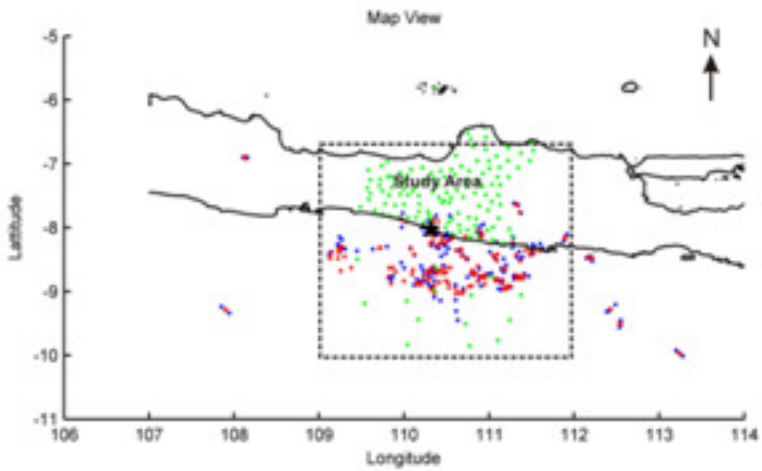

Figure 4: Result of hypocenter relocation by using Hypo-DD method (red) compared to the original hypocenter location (blue) (Koulakov et. al., 2007). Green dots depict the locations of seismographs. 


\section{DEVELOPMENT OF TOMOGRAPHIC SOFTWARE}

The third sub-topic deals with the development of tomographic software. This method could be implemented if following requirements are fulfilled: (1) Hypocenters of microseismic events could be determined in more precise from the application of Hypo-DD method, and (2) Availability of adequate number of seismometers, so that the subsurface cells could be traversed by enough number of seismic rays.

The tomography inversion softwave of FAST (Zelt and Barton, 1998) is used as base for the development of tomographic software. This sub-topic is important, since FAST program is an open source program that could be run only in Sun machine and by using Solaris OS. Since our hardware in laboratory is only ordinary PCs, we have to find out how this program can be installed in ordinary PCs and Linux OS. This effort is the first step that must be done in the beginning.

Basically, this program consists of:

1. Finite difference eikonal solver that is used to calculate travel time from sources to each grid point inside the model (Hole \& Zelt, 1995).

2.Determination of ray path from each shot point to each receiver point inside the model. The ray paths with the minimum travel time can be found by following the steepest gradient in travel time from the receiver back to the source, after the transit time for every grid point inside the model has been calculated.

3. Regularized tomographic inversion developed by Zelt and Barton (1998), which minimizes an objective function that includes norms that measure model roughness and data misfit.

Until now, the installation of FAST program in ordinary PCs is successful for $2 \mathrm{D}$ case. The installation and the use of 3D tomographic software in ordinary $\mathrm{PCs}$ are still carried out now. Furthermore, the 2D tomographic case study has been applied, e.g. for detecting landslide plane in Central Java (Sule and Dani, 2010). Since regularization inversion is included in the program, it has been observed that the tomographic result is more stable than any other available software for first arrival travel time tomography, which indicates the advantage of FAST program.

\section{CONCLUSIONS}

It has been described the progress of research project since it is started 8 months ago. Overall, the progress is beyond the target of $1^{\text {st }}$ year. In the future, the research will be continued intensively in order to realize the development of hardware and user-friendly software of microseismic method.

ACKNOWLEDGMENT: We express our thank to Ministry of Research and Technology of Republic Indonesia for granting this research funding (Reg. nr. KP-2010-3273).

\section{REFERENCES}

1) Aizawa, T., T. Kimura, T. Matsuoka, T. Takao, and Y. Asano, 2008, Application of MEMS accelerometer to geophysics, Intl. Journal of Japanese Committee for Rock Mechanics, Vol. 4, No. 2, pp. $1-4$.

2) Barzilai, A., T. VanZandt, and T. Kenny, 1998, Improving the performance of a geophone through capacitive position sensing and feedback, Proc. of ASME Winter Meeting '98.

3) Asanuma, H., Hotta, A., Manthei, G., and Niitsuma, H., 2006, Relocation of AE events from a compression test of a Rock Salt Specimen by Coherence Collapsing Method, $68^{\text {th }}$ EAGE conference and exhibition, 115-133.

4) Koulakov, I., M. Bohm, G. Asch, B.-G. Lühr, A. Manzanares, K. S. Brotopuspito, Pak Fauzi, M. A. Purbawinata, N. T. Puspito, A.Ratdomopurbo, H. Kopp, W. Rabbel, and E. Shevkunova, 2007, $\mathrm{P}$ and $\mathrm{S}$ velocity structure of the crust and the upper mantle beneath central Java from local tomography inversion, J. Geophys. Res. 112, B08310, doi 10.1029/2006JB004712.

5) Sahara, D. P., A. W. Kusumo, S. Widiyantoro, R. Sule, and H. Asanuma, 2010, High-Resolution Mapping of Microseismic Events by using Double Differential Method, The $4^{\text {th }}$ International Student Conference and Advanced Science and Technology (ICAST), Izmir, Turkey.

6) Sule, R. and I. Dani, 2010, Detection of landslide plane by using refraction seismic tomography method, Proc. of Bali 2010 International Geosciences Conference and Exhibition, Bali - Indonesia.

7) Waldhauser, F., and Ellsworth, W.L., 2000, A double-difference earthquake location algorithm: Method and application to the Northern Hayward fault, California, Bull. Seismol. Soc. Am. 90, 1353-1368.

8) Zelt, C. A. and Barton, P.J., 1998, Three-dimensional seismic refraction tomography: A comparison of two methods applied to data from the Faeroe Basin, J. Geophys. Res., 103, 7187-7210. 